\title{
Knowledge Base Creation and its Use for Teaching Food Security Disciplines to University Students and Postgraduates
}

\author{
Ilya R. Shegelman ${ }^{1 *}$, Olga I. Gavrilova ${ }^{1}$, Alexey S. Vasiliev ${ }^{1}$, Yuriy V. Sukhanov ${ }^{1}$, \\ Pavel O. Shchukin ${ }^{1}$ \\ ${ }^{1}$ Petrozavodsk State University, Russia, Petrozavodsk, RUSSIA
}

Received 16 June 2018 - Revised 20 August 2018 - Accepted 29 September 2018

\begin{abstract}
The relevance of the study is due to the fact that the training of specialists (especially undergraduates and $\mathrm{PhDs}$ ) in any subject field requires deep knowledge in a wide range of generalized information obtained from various sources and represented in the easily perceived visual form. In this regard, this article aims at achieving the aim of examining the basics of information structuring and its presentation in the form of knowledge base when teaching university students and postgraduates the methods and technologies of food security when representing food safety foundations. Petrozavodsk State University gained a unique experience in creating the knowledge base for teaching students and postgraduates under the programs 35.03.01 Forestry, 06.06.01 Biological Sciences, 20.03.01 Technosphere Security in the methods and technologies of food enrichment from the perspective of food security. The knowledge base was created based on the information collected by means of an elaborate data search in literature sources, academic theses, regulatory and patent documents published in Russia and the most advanced countries in the field of food enrichment. Knowledge base represents systemized knowledge intended to teach university undergraduates and postgraduates food enrichment methods and technologies. The knowledge base in the area concerned is growing and will be used for the development of new patentable solutions.
\end{abstract}

Keywords: knowledge base, training, foods, enrichment, sprouts, university

\section{INTRODUCTION}

In recent decades one the most important aspects characterizing economic safety of many countries and regions of the world is the problem of inconsistency between the structure and nutrition of people in these countries and regions and real needs of the population as established by the regulations (Dmitrieva et al., 2015; Platonova et al., 2017). In many remote regions of Russia, a shortage of vitamins and bio-elements, which are found in significant amounts in vegetables, is especially acute (Shegelman, Vasiliev \& Shchukin, 2018a, 2018b; Sharafkhani et al., 2010). One of the possible ways forward for solving this problem is enrichment of food with the sprouted grains, beans and vegetable plants.

This gives rise to a need to make good specialists out of students and postgraduates who already at the stage of studying at the educational institution would immerse into this problem, familiarize with the known modern methods and technologies for achieving the goal and master them.

At present alongside the paper carriers of information the electronic workflow is rapidly developing conversion of paper publications into electronic form, emergence of electronic research papers, electronic libraries, both with free and fee-based access, electronic bases of patent documents, which may be accessed thanks to the global Internet web from any workstation equipped with a computer and connected to the Internet. All of this significantly simplifies and expands access to various documents, both internal and foreign, which helps to

(C) 2018 by the authors; licensee Modestum Ltd., UK. This article is an open access article distributed under the terms and conditions of the Creative Commons Attribution License (http://creativecommons.org/licenses/by/4.0/).

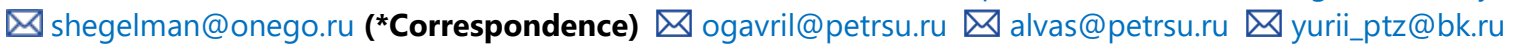




\section{Contribution of this paper to the literature}

- It was revealed that for the improvement of teaching quality of students it is necessary to constantly update educational materials by tracking the emergence of technical and technological innovations. This process should be facilitated by the study of new research publications and analysis of the newest products from the patent fund. It all leads to the accumulation of a large number of scattered information which requires its systematization in the form that is easy to perceive for students and has a clear presentation. Such form of information representation is known as a knowledge base.

- The experience of Petrozavodsk State University in relation to the formation of a knowledge base in the field of food enrichment with seedlings of grain, leguminous and vegetable plants in the food industry from the point of view of ensuring food safety is disclosed.

- The expediency and efficiency of information systematization collected from various sources in the form of structured knowledge bases has been proved. The effectiveness of the knowledge base use in teaching university students and postgraduates is proved.

consolidate big volumes of information. Since the information obtained from diverse sources is scattered, a need appears to systemize the available scientific knowledge related to the subject matter under exploration.

Raising specialists in any subject area, especially when students and postgraduates are concerned, requires a deep knowledge which shall be arranged in a structured way as knowledge bases for the convenience of its use.

\section{LITERATURE REVIEW}

The sprouted grain by a huge energetic value, speed and variety of biochemical transformations has no equivalents in nature (Obrucheva, 1991; Zaytseva et al., 2017). With the sprouts the human body receives in a simple form together with the ferments a complex of necessary nutrients; it is believed that their digestion relieves strain from our body by approximately $90 \%$. Introduction of the sprouts in the diet stimulates the metabolism and the blood formation, strengthens the immunity, compensates for vitamin and mineral deficiencies, normalizes the acidalkaline balance, helps to clean the body of toxins and facilitates the digestion (Safronova, Kazina \& Safronova, 2017). The sprouts of vegetable, grain and bean plans are rich in protein, vitamins and minerals. The sprouts of the seeds of buckwheat, oat, barley and wheat are rich in various aminoacids. They contain considerable amount of mineral salts of iron, calcium, phosphorus, copper, zinc, iodine, boron, nickel, cobalt, etc (Butenko \& Ligaj, 2013). In the process of sprouting most compounds (starch, protein) turn into maltose, glucose, dextrin, peptones, peptides, amino acids, etc. Macro- and microelements are transformed into an easily digestible form (Baulina \& Silant'eva, 2014).

Berezhnaja, Dubcov and Vojno (2015) show the potential of the enriched food based on the grain, which is available to the large sections of population and may improve the quality of food by compensating the lack of biologically active substances in the diet, improve the state of gastrointestinal tract and the body as a whole, enhance its resilience to the adverse external factors. Unfortunately, in our country the sprouted seeds as a wellness product are almost not used.

The study by Safronova, Kazina and Safronova (2017) shows that the sprouted wheat grain may find a wide use in the public catering as a supplement to the diet and vitamin enrichment of ready meals. Kazymov and Prudnikova (2012) recommend sprouted mung beans as digestible raw material for production of functional food items for people suffering from low activity of hydrolytic enzymes in gastrointestinal tract.

The research by Antipova et al. (2017) demonstrates that the use of sprouted lentil seeds in the diet of athletes helps to sustain maximum and sub-maximum loads, reduce fatigue, increase capacity for labour and ensure rapid body recovery in a multi-year process of athletes' preparation.

Demidenko and Zhirnova (2015) offer to use the soy sprouts as a supplement to all kinds of bakery products. The bakery products made of sprouted grain contain more protein, fats, carbohydrates, minerals and vitamins (Obolenskij, Veselova \& Guseva, 2012).

Samofalova (2010) demonstrates potential use of botanical milk substitutes based on the sprouted seeds, since the ferments produced in the process of sprouting decompose compounds into simpler components (amino-acids, fatty acids, simple sugars), multiply increasing the content of vitamins synthesized by the germ.

The recipe and technology for producing fermented milk dessert, enriched with whey proteins and sprouted lentil beans were developed by Baulina and Silant eva (2014). In the other research work the recipe and technology for producing whey product with the use of the sprouted seeds of the haricot bean were developed (Veber et al., 2014). 
The paper of Diowksz, Kordialik-Bogacka and Ambroziak (2014) examines the potential of selenium-enriched sprouted seeds as functional supplements for bread fermentation, as such seeds have the potential to stimulate the growth, and the fermentation effect of lactic acid bacteria. The selenium-enriched rye sprouts, used in the quantity of $2.5 \mathrm{~g}$ per $100 \mathrm{~g}$ of flour, increased selenium content by a factor of 5 .

In the production of enriched semi-processed products used the flour made of sprouted chickpea seeds with the use of potassium iodide solution (Gorlov et al., 2014). During the chickpea seed sprouting the content of protein is increased, leading to activation of ferments, necessary for the synthesis of proteins, flavonoids, carotenoids, enzymes and fatty acids.

In many Asian countries the consumption of the sprouted brown rice is growing due to its excellent nutritional qualities and wellness potential. Sprouting is one of the methods used to improve texture of the cooked brown rice, it causes multiple changes in the composition and chemical structure of bioactive components (Cho \& Lim, 2016).

$\mathrm{Xu}$ et al. (2017) explore the impact of sprouting of the seeds of Coix Lachryma Jobi, used as a source of food (cereals) and as medication in the folk medicine, on the nutritional and physico-chemical properties. Exploration of the nature of changes in nutritional and physico-chemical properties of the seeds of Coix Lachryma Jobi during sprouting demonstrated that 60-hour long sprouting of the seeds of Coix Lachryma Jobi increased by a factor of 3.4 the concentration of $\gamma$-aminobutyric acid and by a factor of 3.6 the concentration of Coixol as compared to the unsprouted seeds of Coix Lachryma Jobi, at the same time the concentration of triolein slightly decreased.

The paper by Wei et al. (2013) studies the influence of iron sulphate enrichment on concentration and bioavailability of iron in the sprouted brown rice. Iron enrichment in the process of sprouting with the iron sulphate $0.05-2 \mathrm{~g} / 1$ increased the iron concentration in the spouted brown rice from 1.1 to 15.6 times as compared to the raw brown rice.

Elmoneim, Elkhalifa and Bernhar (2010) investigate the effect of the grain sprouting on the functional properties of sorghum flour. Functional properties of the flour made of the sprouted seeds of the Sudanese sorghum (Fetarita), which was sprouted for five days, were examined. The results demonstrated that the flour made of sprouted sorghum seeds included highly active proteases and amylases. The sprouted samples had higher solubility of proteins as compared to the reference samples, the highest solubility was observed at pH 6 .

Yiming et al. (2015) analyzed the evolution of nutrient ingredients and antioxidant activity in seeds (shoots) of the Tartar buckwheat (Fagopyrum tataricum (L.) Gaertn) during the sprouting. These studies revealed that the concentration of full flavonoids increased pro rata the duration of sprouting and levelled after the third day of sprouting with changing trends of routine and quercetin, which are ambivalent towards each other. Reduced total content of protein and total content of sugar in the sprouted seeds was accompanied with increased concentration of amino-acids and reduced sugar content.

The paper by Arora, Jood and Khetarpaul (2010) studied the effect of seed germination and probiotic fermentation on the nutritional value of food mixtures based on the barley. The research showed that the combined treatment of food mixtures based on the barley ensured significant improvement in reduced content of sugar, thiamine, niacin, lysine and soluble food fibers in these mixtures. The obtained data helped researchers to conclude that the combination of germination and fermentation has a high potential for improving the quality of food through the use of the nutritional mixtures based on the large grain crops.

The grain bread production technology with the use of the broccoli seeds is described by Malkina and Krjachko (2016). The biologically active substances contained in the broccoli seeds helped to get bread with improved biological value, organoleptic and physico-chemical quality properties, along with the anti-microbial properties.

Multiple publications and patent documents, found at the stage of information gathering, showed that food enrichment with the sprouts is an issue of high importance. A considerable amount of useful information, especially concerning process modes, design and parameters of process equipment is available in descriptions to the invention patent and the utility model patent. But such information is scattered, and its systemization for further use to teach students and postgraduates requires creation of the knowledge bases.

\section{RESEARCH METHODS}

In our country the patent law is not yet sufficiently developed, which is the reason why the study of patents does not receive proper attention, and many teachers does not consider patents as a source of knowledge. Though a considerable lot of results reflected in the invention and utility model patents was obtained through real experimental research. Since patenting is a rather labour-intensive procedure, which requires not only labour, but also financial investments by the applicant, including the annual fee to maintain patent in force, it becomes reasonable to patent only progressive ideas of high value. The patent also contains description of industrial applicability, i.e. how the invention may be used in practice, which helps to check its "feasibility". So information 
obtained from such sources may be trusted with certain confidence. Exploration of the latest patents helps to track emergence of the new technologies and equipment.

As evidenced by the teaching experience of the authors, and the experience of participation in the complex projects implemented by Petrozavodsk State University jointly with the real operating industrial companies (AEM Technologies, Petrozavodskmash, Yarmarka Trade House), the collection and generalization of research and technical information, gathered by exploring and analyzing the content of the academic theses, research publications and patents helps to identify technical level and trends in the subject area, and often to forecast the development path. The effectiveness of such approach is proven by many patents obtained by the authors (more than 100 over the recent 5 years), including with participation of students and postgraduates.

For the convenience of information generalization, presentation and analysis, and first of all, for the convenience of its use for teaching the students, it is reasonable to present it in a systemized manner in the form of the knowledge bases.

The research objective was to create within the frames of studying the food security fundamentals, the knowledge base to teach students and postgraduates in methods and technologies of food enrichment with the sprouts of grains, beans and vegetable plants.

Tasks to be solved included: advanced search for relevant information across a body of publications, standards and patent documents dealing with the enrichment of food with the sprouts of grains, beans and vegetable plants; review of various solutions to enrichment of food with the sprouts of plants in the advanced countries.

\section{RESULTS AND DISCUSSION}

Within the frames of creation of knowledge base on application of the sprouts of grains, beans and vegetable plants in the food industry, an overview of the studies on the problem was given, and the creation and development of the relevant knowledge base for teaching students and postgraduates was initiated. With this purpose the methods and devices for intensifying the emergence and use of the sprouted seeds offered in the Russian inventions and utilities over the recent years were reviewed, and the scientific literature on this topic was examined.

During the creation of the knowledge base all documents were broken down into the categories, for example:

- enrichment by grain germination in water solutions of soluble inorganic salts of certain elements (such patents as RU 2271725, RU 2444211, etc.);

- enrichment with sprouts before packing. The idea is that the cereal is subjected to mechanical treatment (for example, flaking, vapor treatment) in order to ensure its good organoleptic properties and good look. After such treatment the sprouts get damaged. The solution to this problem is offered in patent WO2009063511, and it is as follows: after germination the sprouts shall be separated from the grains, then the grains without the sprouts are subjected to mechanical treatment, and prior to packing of the ready product, the sprouts shall be mixed with (stuck to) the treated grains;

- the application of surface spraying at certain stages of sprouting (such as patents RU 2479197, RU 2444196, etc.);

- soakage in extracts of effective components of the ants, bees, algae, snakes, etc. (such as patent CN 1114539, etc.);

- mixing the ground sprouts with the ground grain basis (such as patents RU 2113128, RU 2187945, etc.);

- using various physical phenomena, such as electromagnetic field, ultrasound, infrared radiation, to facilitate food enrichment with sprouts of grains, beans and vegetable plants.

The undertaken analysis helped to determine in which way to sprout the seeds of various plant crops depending on the pursued goal. The analysis of theoretical and experimental studies described in the academic literature and patent documents helped to derive and systemize the knowledge on the effect of various factors on certain parameters, such as, duration of the sprouted seed soaking in the preservative solution, concentration of the preservative solution, its temperature, intensity of electromagnetic radiation and impact thereof on the properties of the ready food item, and the technological process for its production.

Thus, Petrozavodsk State University obtained experience in creating the knowledge base to teach students and postgraduates in basic technologies of food enrichment with the sprouts of grains, beans and vegetable plants. The knowledge base in the area concerned is growing and will be used for the development of new patentable solutions. 


\section{CONCLUSION}

As a result of the research study, various sources of scientific and technical information were analyzed, such as doctorate theses, research publications, regulatory documents relating to food safety in general and methods of food enrichment in particular; the databanks of the Russian and foreign patent funds were also studied. The information collected was compiled and presented in the form of knowledge bases. The formed knowledge bases allowed to systematize the collected information, present it in the visual and convenient working format. They started to be used in the educational process with undergraduate and postgraduate students of the programs 35.03.01 Forestry, 06.06.01 Biological Sciences, 20.03.01 Technosphere Security to increase their theoretical and practical knowledge in food enrichment methods and technologies from the perspective of food security

The knowledge bases have a lot of advantages. They allow evaluating the technical level achieved by the object under consideration within different time periods, establish trends in its development, identify its development potential as well as easily find an existing solution to the problem, consider close analogues and compare them to each other.

Due to the use of knowledge bases, the authors found a technical solution that provided a precedent for the formation of the application No. 2018123423 "Food Product" and its submission to the Federal Institute of Industrial Property of the Russian Federation in the form of innovation patent; there are also some other important technical solutions undergoing experimental research now and getting ready for patenting.

The experience gained with the formation of knowledge bases has been successful and will be used at Petrozavodsk State University when preparing educational and scientific materials for teaching university students and postgraduates majoring not only in the field of food safety, but also in other specializations in the framework of technical sciences.

\section{ACKNOWLEDGEMENTS}

This research was undertaken with financial support from the Russian Federation represented by the Ministry of Education within the frames of the project "Research and Development of End-to-End Technologies for the Production of Functional Foodstuffs that Enhance Food Security in the Northern Regions of Russia", implemented by Petrozavodsk State University in joint efforts with the Trading House "Yarmarka" (project identifier RFMEFI57717X0264).

\section{REFERENCES}

Antipova, L. V., Grebenwikov, A. V., Miwenko, A. A., Osipova, N. A., \& Tychinin, N. V. (2017). Sprouted seeds of lentils - a source of nutrients and tools for restoring the performance of athletes. Technologies of Food and Processing Industry of the Agroindustrial Complex - Healthy Food Products, 4(18), 69-79.

Arora, S., Jood, S., Khetarpaul, N. (2010). Effect of germination and probiotic fermentation on nutrient composition of barley-based food mixtures. Food Chemistry, 119(2), 779-784. https:/ / doi.org/10.1016/j.foodchem.2009.07.035

Baulina, M. A., \& Silanteva, L. A. (2014). Investigation of the possibility of using sprouted beans of lentils as a prescription component of fermented dessert. Research Journal of NRU ITMO. Series "Processes and Food Industry Apparatus", 2, 4-14.

Berezhnaja, O. V., Dubcov, G. G., \& Vojno, L. I. (2015). Wheat sprouts - an ingredient for foodstuffs. Food Industry, 5, 26-29.

Butenko, L. I., \& Ligaj, L. V. (2013). Studies of the chemical composition of sprouted seeds of buckwheat, oats, barley and wheat. Fundamental Research, 4, 1128-1133.

Cho, D. H., \& Lim, S. T. (2016). Germinated brown rice and its bio-functional compounds. Food Chemistry, 196, 259271. https:// doi.org/10.1016/j.foodchem.2015.09.025

Demidenko, G. A., \& Zhirnova, D. F. (2015). Application of the onion husk extract to produce seedlings of soybean seeds. Herald of Krasnoyarsk State Agrarian University, 3, 94-99.

Diowksz, A., Kordialik-Bogacka, E., \& Ambroziak, W. (2014). Se-enriched sprouted seeds as functional additives in sourdough fermentation, LWT. Food Science and Technology, 56(2), 524-528.

Dmitrieva, N. V., Zaitseva, N. A., Kulyamina, O. S., Larionova, A. A., \& Surova, S. A. (2015). Scientific and Theoretical Aspects of the staff recruitment organization within the concept of "talent management". Asian Social Science, 11(3), 358-365

Elmoneim, A., Elkhalifa, O., \& Bernhar, R. (2010). Influence of grain germination on functional properties of sorghum flour. Food Chemistry, 121(2), 387-392. https:/ / doi.org/10.1016/j.foodchem.2009.12.041 
Gorlov, I. F., Nelepov, Ju. N., Slozhenkina, M. I., Korovina, E. Ju., \& Simon, M. V. (2014). Development of new functional products based on the use of sprouted chickpea. All about Meat, 1, 28-31.

Kazymov, S. A., \& Prudnikova, T. N. (2012). The change in the biological value of the seeds of mung bean during germination. News of Universities. Food Industry, 3, 51-52.

Malkina, V. D., \& Krjachko, T. I. (2016). Prospects of using broccoli processing products in bakery technology. Journal of Research Publications, 6(38), 52-60.

Obolenskij, N. V., Veselova, A. JU., \& Guseva, A. O. (2012). Natural food concentrates - a means of improving the food and biological value of bakery products. Herald of Nizhny Novgorod State Engineering and Economic University, 4, 92-102.

Obrucheva, N. V. (1991). Physiology of the initial stages of seed germination of dicots (DrSc thesis). Moscow.

Platonova, R. I., Zaitseva, N. A., Zemlyanskaya, E. N., Bezborodova, M. A., Stepanov, P. A., \& Mikhina, G. B. (2017). Nonlinear development of university pedagogical system: permanence of didactic tasks. Man in India, 97 (14), 159-171.

Safronova, T. N., Kazina, V. V., \& Safronova, K. V. (2017). Development of technological parameters for germination of wheat grain. Techniques and Technology of Food Industries, 1, 37-43.

Samofalova, L. A. (2010). Scientific substantiation of the application of germinating seeds of dicotyledonous plants in the production of plant base and substitutes for dairy products of functional significance (DrSc). St. Peterburg.

Sharafkhani, R., Dastgiri, S., Gharaaghaji, R., Ghavamzadeh, S., Didarloo, A. (2010). The Role of Household Structure on The Prevalence of Food Insecurity. European Journal of General Medicine, 7(4), 385-388. https:/ / doi.org/10.29333/ejgm/82890

Shegelman, I., Vasiliev, A., \& Shchukin, P. (2018a). Particularities of ensuring food security in the conditions of the north of Russia. Astra Salvensis, 6, 941-949.

Shegelman, I., Vasiliev, A., \& Shchukin, P. (2018b). The analysis of experience of advanced countries in solving food security problems. Astra Salvensis, 6, 899-907.

Veber, A. L., Kazydub, N. G., Fialkov, D. M., Bujakova, A. A., \& Bujakova, T. A. (2014). Development of technology of a fermented milk product with bean sprouts. Herald of Omsk State Agrarian University, 2(14), 63-66.

Wei, Y., Shohag, M., Ying, F., Yang, X., Wu, C., \& Wang, Y. (2013). Effect of ferrous sulfate fortification in germinated brown rice on seed iron concentration and bioavailability. Food Chemistry, 138(3), 1952-1958. https://doi.org/10.1016/j.foodchem.2012.09.134

Xu, L., Chen, L., Ali, B., Yang, N., Chen, Y., Wu, F., Jin, Z., \& Xu, X. (2017). Impact of germination on nutritional and physicochemical properties of adlay seed. Food Chemistry, 229, 312-318. https://doi.org/10.1016/j.foodchem.2017.02.096

Yiming, Z., Hong, W., Linlin, C., Xiaoli, Z., Wen, T., \& Xinli, S. (2015). Evolution of nutrient ingredients in tartary buckwheat seeds during germination. Food Chemistry, 186, 244-248. https://doi.org/10.1016/j.foodchem.2015.03.115

Zaytseva, N., Larionova, A., Zhukov, V., \& Pervunin, S. (2017). Role of employers in the formation of educational programs and resources for training of specialists in service sphere. Journal of Educational Management, 31 (1), 3-11. https:/ / doi.org/10.1108/IJEM-02-2016-0034

\section{http://www.ejmste.com}

